\title{
One-Stop General Practice
}

I work in a large suburban general practice clinic. We are 9 general practitioners, 6 dentists as well as a dietician, a psychologist and a pharmacy. We have 5 nurses, 3 day beds, 2 procedure rooms, and an X-ray department. A pathology laboratory collects blood tests about 4 times a day from the clinic.

The other day a patient came in to see me for my $8.00 \mathrm{am}$ appointment. She said she had a small pigmented mole on her shoulder that had appeared three months ago. I took her down to one of the procedure rooms where one of the nurses laid out an excision tray and I injected local anaesthesia. I used one ampoule of lignocaine with adrenaline under each end of the mole and then one ampoule of plain lignocaine at the sides, and lifted the mole off the underlying tissues with the local anaesthetic (8 minutes). I then scrubbed up and put a number 15 blade on the scalpel handle and unwrapped a number 3 nylon suture and fixed it on the needle holder by which time the local had worked (5 minutes). I then cut the mole out including a margin of skin ( 2 minutes) and then stitched up the skin (4 minutes) while talking with the patient about the unseasonable weather we are having at the moment and also about her daughter in Australia. Happily the histology received later was a benign pigmented dermatofibroma.

This patient was in and out of the rooms in under half an hour and afterwards went back to work. In many countries in the world she would have been referred to the local hospital (one day lost from work) and then told to come back for the procedure at another date (another day lost from work). Long ago there was a study from the NHS in the United Kingdom that worked out that it was 15 times more expensive to refer small procedures such as these to hospitals.

There are several other situations where comprehensive general practice saves money and saves the country millions in saved work time. Patients with gastroenteritis and dehydration who have been up all night with diarrhoea and vomiting get intravenous hydration and medication in one of our day beds and may be back at work in the afternoon. An asthmatic can get intravenous medications and nebulisation in our nebulisation room. She can then get back to her business meeting on time. Patients with minor lacerations are stitched within an hour and off they go.
It is not only procedural general practice that is wellorganized. Diagnostic processes can be fast and efficient. A patient of mine came in from Mozambique with a fever and I had the positive malarial blood test back in three hours. In cases of chest pain we do a finger prick Troponin enzyme and send a full test for cardiac enzymes off to the laboratory even if they have a normal ECG and the results are back very quickly. This takes a lot of burden off hospital emergency departments.

One last example is a patient who came into to see me recently and said he seemed to have difficulty in breathing. "Sometimes I feel I cannot get air in," he said. He had no chest pain and was fit except for moderate hypertension that was controlled. He had no leg or abdominal pain or evidence of a DVT. The chest was normal to auscultation but I am an old fashioned pulse, temperature and dipstick-in-the-urine doctor. I get an extraordinary amount of information from these signs and tests. His temperature was normal but his pulse rate was raised to 108 per minute. This was the only physical sign, but for me this is a pulmonary embolism until proven otherwise. We went down the corridor to X-ray and the chest X-ray was normal ( 25 minutes). One relaxes a bit at this stage but microemboli are still not excluded. Off goes the D-dimer and the patient goes home. A D-dimer result takes about 2 hours to come back so I phoned him later in the day to tell him to go to hospital as the D-dimer was positive. Lung scans showed multiple microemboli. He now thinks I am the most amazing doctor. As you know, I can take praise in any form you would like to give it. Just ladle it on in thick layers.

This is not to say that everything is perfect in our clinic. Things still go wrong. I get tired, the staff get sick, the equipment breaks. On some days everything falls apart. This is the same for any service that requires multiple functioning parts in the chain of delivery. Even though we work in a state-of-the-art clinic we spend a lot of time, over tea, whinging about anything that we can find wrong - especially the performance of the Proteas' middle order batting.

Despite these occasional hiccups it is a privilege to work in this system. It makes the practice of medicine both efficient and rewarding.

Chris Ellis is a family physician in Pietermaritzburg, KwaZulu-Natal

E mail: cristobalellis@gmail.com 